\title{
Biocomércio em comunidades tradicionais: uma revisão sistemática
}

\author{
Biotrade in traditional communities: a systematic review
}

\author{
Marcelo Elias dos Santos ${ }^{1}$ \\ Lara Bartocci Liboni ${ }^{2}$
}

\begin{abstract}
Resumo
As principais características do modo de vida das comunidades tradicionais garantem a conservação dos recursos naturais. Porém, as políticas públicas demonstram uma lógica oposta a esse comportamento ao tentar integrar as comunidades aos grandes centros urbanos do país. Esse pensamento, remete a ideia de que as comunidades são apenas fornecedoras de matérias-primas com potencial para ter valor adicionado. Assim, para analisar as relações comerciais das comunidades tradicionais de outra perspectiva, utilizou-se o conceito de biocomércio que compreende desde a coleta até a comercialização dos produtos da biodiversidade, considerando os critérios de sustentabilidade. Nesse sentido, o presente artigo teve como como objetivo apresentar um quadro conceitual sobre o biocomércio entre comunidades tradicionais e empresas privadas. Para tanto, recorreu-se a um estudo metodológico de revisão sistemática da literatura em teses e dissertações. A pesquisa foi desenvolvida em três fases e classificou 73 pesquisas em 6 categorias. $\mathrm{Na}$ última fase, foram identificados 11 trabalhos que estudaram o comércio de produtos da biodiversidade, porém, apenas uma pesquisa analisou um contrato de fornecimento de produto da biodiversidade. Os produtos estudados nas pesquisas confirmaram o potencial da biodiversidade brasileira, no entanto, há casos de biopirataria, redução da disponibilidade de recursos internos e disputas territoriais. O quadro conceitual proposto considera três abordagens interdependentes. É possível posicionar novos temas de pesquisa e utilizar critérios que até o momento receberam muita ou nenhuma atenção para dar relevância ao estudo. As diretrizes e princípios do biocomércio complementam a análise, posicionando adequadamente a pesquisa dentro dos critérios de sustentabilidade.
\end{abstract}

Palavras-chave: Biocomércio. Biodiversidade. Comunidades Tradicionais.

\begin{abstract}
The main characteristics of the way of life of traditional communities guarantee the preservation of natural resources. However, public policies demonstrate logic opposite to this behavior when trying to integrate the communities into the large urban centers of the country. This thought refers to the idea that communities are only suppliers of raw materials with potential to have added value. Thus, in order to analyze the commercial relations of traditional communities from another perspective, the concept of biotrade was used, from the collection to the commercialization of biodiversity products, taking into account the sustainability criteria. Therefore, the objective of the present article was to show a conceptual framework on biotrade between traditional communities and private companies. For this, a methodological study based on a systematic literature review of theses and dissertations was used. The study was developed in three phases and classified 73 publications into six categories. In the last phase, 11 papers were identified that addressed the trade

\footnotetext{
${ }^{1}$ Doutorando em Administração de Organizações pela FEA-RP-USP. E-mail: santosmarceloelias@ gmail.com

${ }^{2}$ Professora Associada do Departamento de Administração, da FEA-RP-USP. E-mail: lara.liboni@gmail.com
} 
of biodiversity products; however, only one study analyzed a contract for the supply of a biodiversity product. The products studied in the papers confirmed the potential of Brazilian biodiversity; nevertheless, cases of biopiracy, reduction of the availability of internal resources, and territorial disputes were found. The proposed conceptual framework considers three interdependent approaches. It is possible to propose new research themes and use criteria that until now have received little or no attention to give relevance to this study. The guidelines and principles of biotrade complement the analysis, properly positioning the present study within the criteria of sustainability.

Keywords: Biotrade. Biodiversity. Traditional communities.

\section{Introdução}

Aliada a preocupação crescente entre o padrão de consumo e origem da matéria-prima, o setor empresarial vem reconhecendo as oportunidades de negócio que a biodiversidade brasileira oferece (MORSELLO, 2006) e, desta forma, investe em produtos que atendam essas expectativas e ao mesmo tempo incorporem valores socioambientais, fato que motiva o desenvolvimento de produtos com base na biodiversidade pela indústria alimentícia, de cosméticos, farmacêutica e também pelo setor de serviços como o ecoturismo (BERKES; COLDING; FOLKE, 2000).

Nas últimas décadas, os produtos da biodiversidade têm sido revalorizados e a sua utilização incrementada com a valorização de uma vida com hábitos saudáveis e consumo de produtos naturais. A biodiversidade tem sido vista como um grande potencial econômico, no entanto, as regiões produtoras apresentam como característica a diversidade de grupos étnicos constituídos em vários processos de colonização e miscigenação. Nessa perspectiva, são adotadas as políticas públicas marcadas pelos interesses e estratégias de expansão das relações comerciais que influenciam o modo de vida das comunidades tradicionais (LIRA; CHAVES, 2016).

De acordo com Diegues (2000), as principais características do modo de vida das comunidades tradicionais garantem a conservação dos recursos naturais. As comunidades combinam várias atividades econômicas de forma responsável, geram baixo nível de poluição, dependem dos recursos e ciclos naturais, possuem reduzida acumulação de capital, mantem simbologias, mitos e rituais e sua tecnologia é relativamente simples (ENRÍQUEZ, 2009; MEDINA; BARBOSA, 2016; SOUSA; PEZZUTI, 2017).

Ao considerar essas características, Pawar (2003) informa que aumentou o número de trabalhos com o objetivo de reviver os principais elementos das comunidades tradicionais. Por outro lado, características importantes como o modelo de ocupação do espaço, uso dos recursos naturais 
voltado para a subsistência, uso de mão de obra familiar e tecnologias de baixo impacto, contrastam com a fraca articulação com o mercado. Outro aspecto negativo destacado por Lobato et al. (2014), é que os traços da modernidade estão modificando os antigos hábitos, como uso de medicamentos caseiros e contribuem com o declínio do conhecimento tradicional (PARDO-DE-SANTAYANA; MACÍA, 2015; TANG; GAVIN, 2016).

Em muitos aspectos, para Chaves (2009), as políticas públicas na Amazônia possuem lógicas opostas aos interesses e demandas de vastos segmentos das populações amazônicas, tendo em vista a mesma justificativa baseada na necessidade de "desenvolver" e "integrar" a região aos grandes centros comerciais do país e ao mercado internacional. Essa linha de pensamento, remete a ideia de que durante todo o processo de formação e desenvolvimento, a região amazônica sempre foi vista como uma fornecedora de commodities, principalmente produtos com potencial para se adicionar valor do tipo comestíveis, temperos e ingredientes alimentícios, cosméticos e substâncias farmacêuticas e aquacultura.

Para investigar o fornecimento de produtos da biodiversidade de forma equilibrada, esta pesquisa considera o conceito de biocomércio, proposto pela United Nations Conference on Trade and Development (UNCTAD, 2006, p. 1), como "um conjunto de atividades de coleta, produção, transformação e comercialização de bens e serviços derivados da biodiversidade nativa, que se aplicam critérios de sustentabilidade ambiental, social e econômica”. Dificilmente todas essas dimensões serão observadas na mesma proporção em um território ou produto, mas não deixam de constituir a base para implementar um processo de melhoria contínua que tem o biocomércio como fim.

Diante do exposto, entende-se que as comunidades tradicionais estão firmando acordos com diversos atores interessados em produtos da biodiversidade, porém, apenas alguns contratos priorizam os princípios do biocomércio. Nesse sentido, o presente artigo teve como objetivo apresentar um quadro conceitual sobre o biocomércio entre comunidades tradicionais e empresas privadas, e entre outras inquietações, pretende responder a questão: qual a situação atual da agenda de pesquisas sobre o biocomércio em comunidades tradicionais no Brasil?

\section{Comunidades tradicionais e o biocomércio}

Neste artigo, parte-se do entendimento de que povos e comunidades tradicionais são grupos culturalmente diferenciados que possuem formas próprias de organização social, ocupam e usam 
territórios e recursos naturais como condição para sua reprodução cultural, social, religiosa, ancestral e econômica (BRASIL, 2007). As comunidades tradicionais são grupos assentados em territórios delimitados, com identidade cultural forte e diferente da nacional. Os membros têm modos de ser, fazer e viver distintos da sociedade em geral, com identidades e direitos próprios, por exemplo, andirobeiras, catingueiros, caiçaras, castanheiras, catadores de mangaba, ciganos, cipozeiros, extrativistas, faxinalenses, fundo e fecho de pasto, geraizeiros, indígenas, isqueiros, pantaneiros, pescadores artesanais, povos de terreiro, quebradeiras de coco de babaçu, quilombolas, retireiros, ribeirinhos e seringueiros (KANTEK, 2009).

Apesar das ondas de modernização as comunidades tradicionais continuam com sua forma de viver através do compartilhamento por todo o mundo. De acordo com Pawar (2003), se há comprometimento em reconstruir a vida comunitária, devemos olhar para essas comunidades e estudar sua autossuficiência. Para isso, é importante conhecer suas expressões culturais próprias e o repertório de mitos, ritos e conhecimentos herdados de ancestrais que são passados de geração em geração e administrados coletivamente. Além das técnicas associadas ao uso de recursos renováveis e tecnologias de baixo impacto ambiental, que respeitam os limites e exploram as potencialidades dos territórios tradicionais (BRASIL, 2007).

A base da cultura dessas populações são os recursos naturais, que têm em seu modo de vida uma relação íntima com o meio ambiente (CALEGARE; HIGUCHI; BRUNO, 2014). Elas seguem os ciclos naturais e um complexo calendário agrícola ou pesqueiro. Há o tempo para fazer a coivara, preparar a terra, semear, capinar e colher, como também há o tempo de se esperar as espécies de peixes migratórios. Uma vez terminado esse ciclo, ele recomeçará no período seguinte. Em muitas comunidades, as atividades são comandadas por sinais, como a mudança da lua, chuva etc. Esses ciclos são muitas vezes celebrados por festividades que marcam o início ou o fim de determinada safra (LIMA; KAPLAN; DORIA, 2017).

A relação entre comunidades e o ambiente biofísico por elas ocupadas conjuga múltiplos fatores, interferindo em trajetórias que definem meios de vida e levam a mudança no uso e cobertura da terra (PORRO; PORRO, 2015). Nesta relação, destacam-se formas diferentes de acesso aos recursos, de propriedade, de sistema de produção, de interação com o mercado (SOUSA; PIRAUX, 2015). Outras influências partem da modalidade de ação coletiva, relações de gênero, estágios das unidades domésticas e processos de diferenciação econômica intrafamiliares e interfamiliares, assim como a intervenção externa. 
Uma forma de relacionamento com a biodiversidade que tem recebido atenção é o biocomércio, o termo e a Iniciativa para o Biocomércio foram criados em 1996 pela UNCTAD como um instrumento para os países harmonizarem o desenvolvimento econômico com a conservação da biodiversidade através do comércio de bens e produtos derivados da biodiversidade. O objetivo da iniciativa é contribuir para a conservação e uso sustentável da biodiversidade através da promoção do comércio e investimento em produtos e serviços, de acordo com os objetivos e princípios da Convenção sobre Diversidade Biológica (CDB).

Para UNCTAD (2006) um produto é considerado como de biocomércio quando atende sete princípios: P1. Conservação da biodiversidade; P2. Uso sustentável da biodiversidade; P3. Distribuição justa e equitativa dos benefícios derivados do uso da biodiversidade; P4. Sustentabilidade socioeconômica; P5. Cumprimento da legislação nacional e internacional; P6. Respeito pelos direitos dos atores envolvidos e P7. Clareza na posse da terra, uso e acesso a recursos naturais e conhecimento. Os princípios e critérios do biocomércio estão alinhados com os objetivos e princípios da CDB, a Comissão de Desenvolvimento Sustentável (CDS) e as Metas de Desenvolvimento do Milênio (MDM).

O biocomércio promove o comércio sustentável e responsável da biodiversidade, conjugando práticas de conservação e uso sustentável que geram prosperidade. Dentro dos princípios e critérios propostos, o biocomércio busca incorporar boas práticas de gestão ambiental, inclusão social e desenvolvimento econômico, proporcionando uma mudança qualitativa na forma em que os setores produtivos se relacionam com a biodiversidade e as comunidades possuidoras de conhecimento tradicional, podendo passar de uma perspectiva de exploração intensiva a um relacionamento mais ético (BANCO DE DESARROLLO DE AMÉRICA LATINA (CAF), 2014).

\section{Métodos}

\section{Tipo da pesquisa}

Para consecução do objetivo desse trabalho, recorreu-se a um estudo metodológico de revisão sistemática da literatura em teses e dissertações de Programas de Pós-Graduação no Brasil. As seções prévias permitiram identificar algumas características relevantes das comunidades tradicionais e questionar: qual a situação atual da agenda de pesquisas sobre o biocomércio em comunidades tradicionais no Brasil? Entende-se que empreender um mapeamento das pesquisas 
atuais sobre comunidades tradicionais com ênfase no biocomércio, entre outros benefícios, será útil para comunidade científica e servirá como insumo para novos estudos na área (JABBOUR, 2013; TANGA; GAVIN, 2016).

A pesquisa foi conduzida de acordo com as recomendações de Huisingh (2012), Jabbour, (2013) e Mwilua, Comyn-Wattiaua e Prat (2016), com o objetivo de integrar os resultados de diversos estudos sobre os temas comunidades tradicionais e biocomércio, além disso fornecer um mapeamento das principais pesquisas realizadas. Do ponto de vista das motivações, a pesquisa pretende identificar eventuais lacunas na literatura e posicionar adequadamente novas inciativas de investigação sobre a relação de comunidades tradicionais com o biocomércio (KITCHENHAM; BRERETON, 2013).

A pesquisa foi limitada para teses e dissertações publicadas no Brasil com o objetivo de aumentar sua abrangência de temas e casos pesquisados e não publicados em periódicos. Considerando os trabalhos selecionados, foi realizada uma pesquisa no Currículo Lattes (CL) <lattes.cnpq.br/> dos autores em dezembro de 2018 que apontou um pequeno número de trabalhos publicados. Na segunda fase da pesquisa, foram selecionadas 50 pesquisas das quais apenas 27 foram publicadas. Na terceira fase, das 11 pesquisas selecionadas, apenas 2 foram publicadas em periódicos. Assim, justifica-se a revisão em teses e dissertações por apresentarem as produções mais recentes sobre o tema e por corroborarem com o objetivo do mapeamento de identificar lacunas na literatura e posicionar adequadamente novas pesquisas.

\section{Fases da pesquisa}

A fase de inclusão, pesquisa no banco de dados, foi conduzida no período de 18 à 25 de julho de 2018 no Banco de Teses \& Dissertações da Capes <http://bancodeteses.capes.gov.br/banco-teses/>, limitada ao período de 2002 à 2016. O levantamento consistiu em uma pesquisa na base de dados com os strings de busca: <biodiversidade AND (Brasil OR Brazil) AND conhecimento tradicional AND (comunidade* tradicional*) AND (parceria*)>, como sugere Rowe (2014). Ao final desta fase, foram selecionados 73 trabalhos.

A segunda fase da pesquisa, exclusão pelo contexto, consistiu em ler os resumos e identificar os seis critérios de classificação descritos no Quadro 1. Para cada classificação há mais de uma resposta possível, assim, as respostas para cada pergunta foram tabuladas e apresentados os percentuais para cada opção. Dessa forma, após a análise, 50 estudos foram considerados para a pesquisa e os trabalhos que não tratavam sobre comunidades tradicionais (por exemplo, legislação 
sobre as Unidades de Conservação) foram descartados como sugerem (JABBOUR, 2013; UNG, HARNETT; HU, 2017).

QUADRO 1. SEGUNDA FASE, PERGUNTAS SOBRE O CONTEXTO.

1. Qual foi o bioma pesquisado?

2. Qual foi o foco da pesquisa?

3. Qual foi o método utilizado?

4. Qual comunidade tradicional foi pesquisada?

5. Qual a principal dificuldade identificada?

FONTE: Org. dos Autores (2019).

A terceira fase, exclusão por conteúdo, consistiu em analisar as 50 pesquisas da fase anterior a partir das questões propostas no Quadro 2. Nesta fase, foram identificados os trabalhos que de fato estudaram uma comunidade tradicional e considerando seu principal produto analisou as relações comerciais com empresas privadas, mercado local e consumo interno. Os trabalhos que não tiveram esse objetivo, foram descartados, assim como os trabalhos que não apresentaram os benefícios e as principais práticas de gestão identificadas. Ao final dessa fase, foram selecionados 11 trabalhos.

QUADRO 2. TERCEIRA FASE, BIOCOMÉRCIO.

6. Qual o principal produto da comunidade?

7. A comunidade possui um acordo para fornecimento de matéria-prima?

8. Como é a gestão do negócio?

9. Quais são os impactos positivos?

10. Quais são os impactos negativos?

FONTE: Org. dos Autores (2019).

$\mathrm{Na}$ quarta fase, quadro conceitual, os resultados dos dois processos de filtragem foram utilizados para compor um quadro conceitual que reúne as categorias de pesquisa e os princípios e abordagens do biocomércio como forma de oferecer sugestões para futuras pesquisas. 


\section{Resultados e discussão}

Observou-se que, $50 \%$ das teses e dissertações optaram por pesquisar um bioma específico, a Amazônia, considerada a maior reserva do mundo e o maior bioma do Brasil. A Amazônia ocupa quase metade $(49,29 \%)$ do território nacional e escoa $20 \%$ do volume de água doce do mundo (INSTITUTO BRASILEIRO DE GEOGRAFIA E ESTATÍSTICA (IBGE), 2010). Para Mello (2013), o menor volume de pesquisas sobre os demais biomas, tem relação com a escassez de trabalhos sobre o uso sustentável da biodiversidade.

O principal foco foi a biodiversidade, presente em $60 \%$ das pesquisas que priorizaram a riqueza e a variedade do mundo natural. Um número menor de trabalhos explorou os recursos genéticos de valor comercial (6\%) e a manipulação e comercialização de recursos biológicos (4\%). Sobre a bioprospecção e biopirataria, Enríquez (2008) afirma que novos estudos podem explorar produtos para a bioindústria e ao mesmo tempo garantir os direitos das comunidades tradicionais evitando a pilhagem da natureza e a apropriação ilegal (ATTUCH, 2006; PORRO; PORRO, 2015).

Destaca-se que $34 \%$ das pesquisas utilizaram o método qualitativo e $20 \%$ estudo de caso. A quantidade de pesquisas com a combinação de métodos qualitativos e quantitativos foi de (24\%), pesquisas exclusivamente quantitativas ou conceituais apareceram no mesmo número (8\%). A menor quantidade de trabalhos quantitativos reflete as dificuldades enfrentadas pelo pesquisador nas pesquisas de campo, trata-se de uma tarefa exigente que demanda preparação para lidar com a logística, comunicação, a própria natureza e o planejamento financeiro.

As comunidades mais frequentes foram quilombolas (24\%), ribeirinhos (20\%) e caiçaras (18\%). É comum alguns produtores rurais declararem pertencentes a determinada atividade e ao mesmo tempo ter outras ocupações como agricultura, pesca e extrativismo. Quanto ao extrativismo, há muita resistência em declará-lo como atividade principal, os trabalhadores relatam essa atividade na maioria das vezes como secundária.

O Patrimônio Biocultural Imaterial (PBI) corresponde ao patrimônio cultural (folclore, valores espirituais, o conhecimento, inovações e práticas) e patrimônio biológico (diversidade de genes, variedades e serviços culturais) das comunidades tradicionais (INTERNATIONAL SOCIETY OF ETHNOBIOLOGY (ISE), 2006) e é composto por três grandes grupos de recursos bioculturais imateriais, recursos da diversidade biológica, conhecimentos tradicionais e expressões culturais tradicionais. Feitas essas considerações, os resultados demonstram que são mais numerosos os estudos que trabalharam com recursos da diversidade biológica (46\%). 
Dentre as diversas dificuldades que as comunidades tradicionais enfrentam, a mais presente nas pesquisas foi a descaracterização da comunidade (22\%), seguida por atividades humanas conflitantes (18\%). Outra dificuldade recorrente em várias comunidades está relacionada a manutenção e reconquista do território. Para Diegues (2000), a expulsão de suas terras implica a impossibilidade de continuar existindo como grupo portador de determinada cultura.

FIGURA 1. DISTRIBUIÇÃO DAS ANÁLISES DAS CLASSIFICAÇÕES E CATEGORIAS.

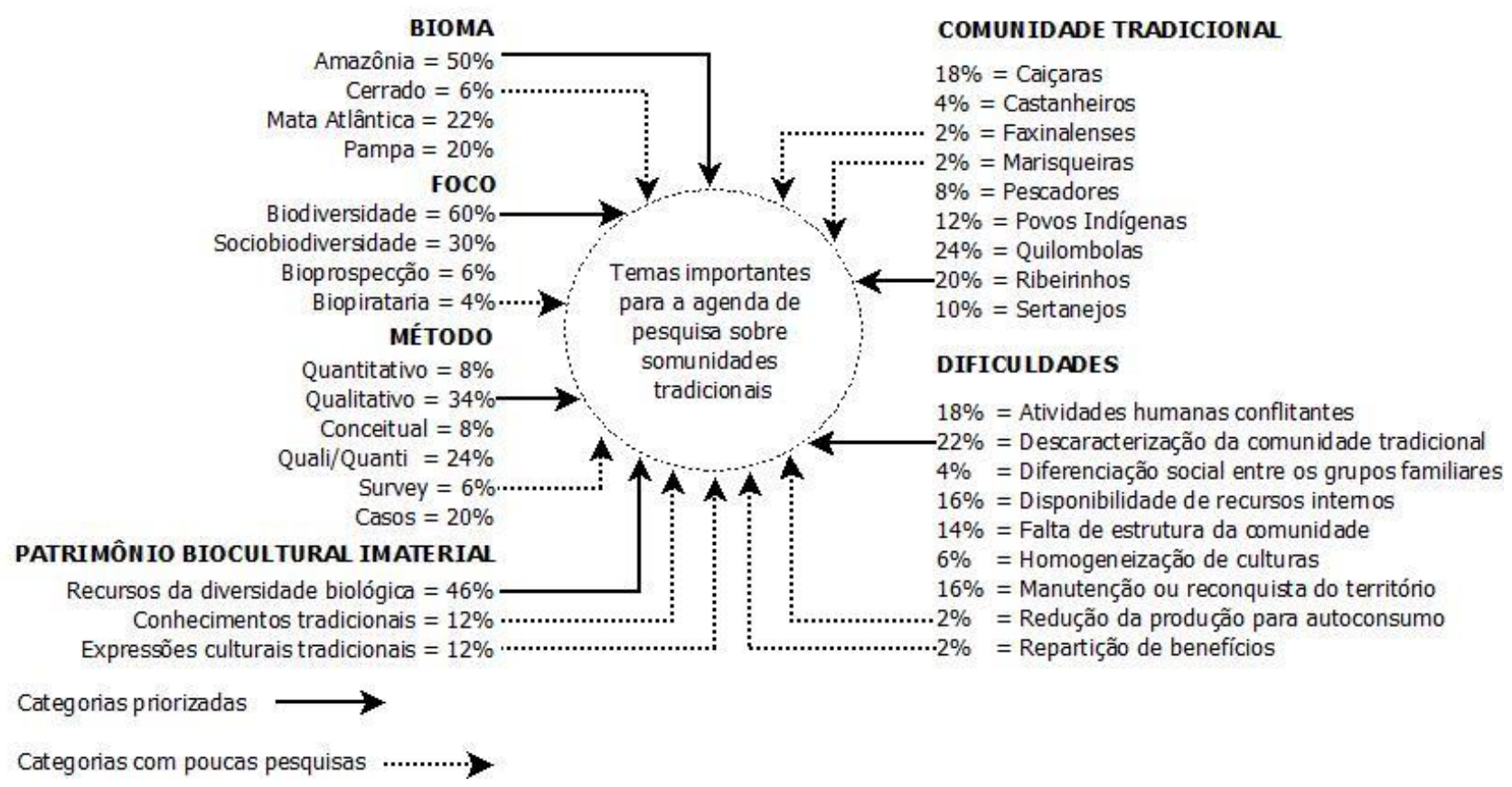

FONTE: Org. dos Autores (2019).

A terceira fase, exclusão por conteúdo, revisitou os 50 trabalhos da etapa anterior com o objetivo de filtrar aqueles que avaliaram uma relação comercial entre uma comunidade tradicional e uma empresa. Identificou-se que as publicações com esse foco iniciaram em 2007 e a maior quantidade de pesquisas foram produzidas em 2014, de acordo com o Gráfico 1. 

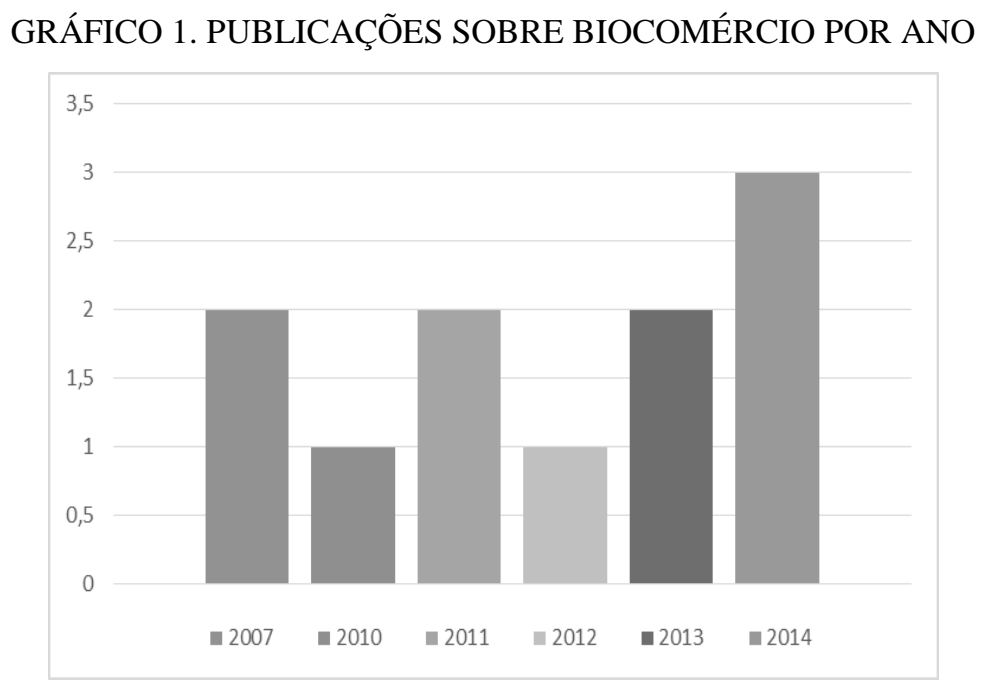

FONTE: Os Autores (2019).

Quanto a região de origem das universidades onde são realizadas as pesquisas, destaca-se a Região Sudeste com 5 pesquisas e a Região Centro-Oeste com quatro. As principais universidades são Universidade de São Paulo (USP) e Universidade de Brasília (UNB), conforme o Gráfico 2.

GRÁFICO 2. PUBLICAÇÕES SOBRE BIOCOMÉRCIO POR REGIÃO DO BRASIL

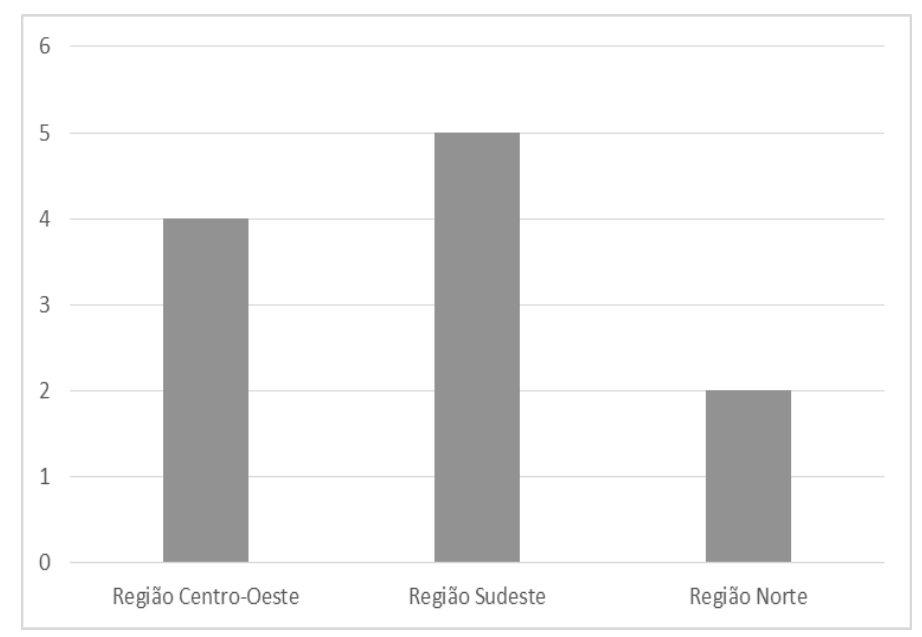

FONTE: Os Autores (2019).

Os 11 trabalhos selecionado são apresentados no Quadro 3, que sintetiza as principais características dessas pesquisas, que em seu desenvolvimento, de maneira direta ou indireta abordaram o biocomércio. 
QUADRO 3. PRINCIPAIS CARACTERÍSTICAS DAS PESQUISAS QUE AVALIARAM RELAÇÕES COMERCIAIS.

\begin{tabular}{|c|c|c|c|c|c|c|c|c|c|c|c|}
\hline & $\begin{array}{c}\text { Cavalcanti } \\
(2010)\end{array}$ & $\begin{array}{c}\text { Fabiano } \\
(2011)\end{array}$ & $\begin{array}{l}\text { Falcão } \\
(2013)\end{array}$ & $\begin{array}{l}\text { Faria } \\
(2007)\end{array}$ & $\begin{array}{l}\text { Gomes } \\
(2007)\end{array}$ & $\begin{array}{l}\text { Melo } \\
(2013)\end{array}$ & $\begin{array}{c}\text { Pereira } \\
(2012)\end{array}$ & $\begin{array}{l}\text { Silva } \\
(2014)\end{array}$ & $\begin{array}{l}\text { Souza } \\
(2014) \\
\end{array}$ & $\begin{array}{c}\text { Trindade } \\
\text { (2011) }\end{array}$ & $\begin{array}{l}\text { Vieira } \\
(2014)\end{array}$ \\
\hline نَّ & $\begin{array}{l}\text { Produtores } \\
\text { rurais de } \\
\text { Barra do } \\
\text { Turvo-SP e } \\
\text { Registro-SP }\end{array}$ & $\begin{array}{l}\text { Resex } \\
\text { Marinha de } \\
\text { Arraial do } \\
\text { Cabo-RJ }\end{array}$ & $\begin{array}{l}\text { Resex de Soure, } \\
\text { Soure-PA e Mãe } \\
\text { Grande, Curuçá- } \\
\text { PA }\end{array}$ & $\begin{array}{l}\text { Povo Araweté, } \\
\text { Ipixuna-PA }\end{array}$ & $\begin{array}{l}\text { Comunidades } \\
\text { Vila Velha do } \\
\text { Cassiporé, } \\
\text { Oiapoque-AM }\end{array}$ & $\begin{array}{l}\text { Cooperval, } \\
\text { Formosa-GO }\end{array}$ & $\begin{array}{l}\text { Comunidade } \\
\text { Mumbuca, } \\
\text { Mateiros-TO }\end{array}$ & $\begin{array}{l}\text { Comunidade } \\
\text { quilombola } \\
\text { Mandira, } \\
\text { Cananéia-SP }\end{array}$ & $\begin{array}{l}\text { Parque } \\
\text { Estadual da } \\
\text { Serra do Mar- } \\
\text { SP }\end{array}$ & $\begin{array}{l}\text { Povo } \\
\text { Wapichana- } \\
\text { RO }\end{array}$ & $\begin{array}{l}\text { Comunidades } \\
\text { tradicionais da } \\
\text { Amazônia-PA }\end{array}$ \\
\hline 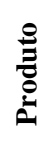 & $\begin{array}{l}\text { Pariparoba e } \\
\text { folhas secas } \\
\text { de maracujá- } \\
\text { doce }\end{array}$ & $\begin{array}{l}\text { Turismo e } \\
\text { Pesca }\end{array}$ & Turismo & $\begin{array}{l}\text { Sementes de } \\
\text { mogno }\end{array}$ & Turismo & Baru & $\begin{array}{l}\text { Capim } \\
\text { dourado }\end{array}$ & Ostra & $\begin{array}{l}\text { Juçara e } \\
\text { Frutos }\end{array}$ & $\begin{array}{l}\text { Cunani e } \\
\text { Biribiri }\end{array}$ & $\begin{array}{l}\text { Mandiocas } \\
\text { açucaradas }\end{array}$ \\
\hline 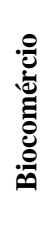 & $\begin{array}{l}\text { Contrato de } \\
\text { fornecimento } \\
\text { com empresa } \\
\text { de cosméticos }\end{array}$ & $\begin{array}{l}\text { Prestação } \\
\text { de serviço } \\
\text { turístico e } \\
\text { pesca } \\
\text { artesanal }\end{array}$ & $\begin{array}{l}\text { Prestação de } \\
\text { serviço turístico }\end{array}$ & $\begin{array}{l}\text { Venda de } \\
\text { sementes para } \\
\text { colonos e } \\
\text { fazendeiros da } \\
\text { região }\end{array}$ & $\begin{array}{l}\text { Prestação de } \\
\text { serviço turístico }\end{array}$ & $\begin{array}{l}\text { Extrativismo do } \\
\text { baru com } \\
\text { finalidade } \\
\text { comercial }\end{array}$ & $\begin{array}{l}\text { Venda do } \\
\text { artesanato de } \\
\text { capim dourado } \\
\text { aos turistas }\end{array}$ & $\begin{array}{l}\text { Comercialização } \\
\text { em uma feira } \\
\text { agroecológica }\end{array}$ & $\begin{array}{l}\text { Venda de } \\
\text { polpa } \\
\text { congelada } \\
\text { para o } \\
\text { consumidor } \\
\text { final }\end{array}$ & $\begin{array}{l}\text { Produção de } \\
\text { fármacos a } \\
\text { partir de } \\
\text { cunani e } \\
\text { biribiri }\end{array}$ & $\begin{array}{l}\text { Venda das } \\
\text { mandiocas } \\
\text { açucaradas para } \\
\text { produção de etanol }\end{array}$ \\
\hline 怤 & $\begin{array}{l}\text { Organização } \\
\text { social do } \\
\text { grupo e falta } \\
\text { de uma } \\
\text { plataforma } \\
\text { para ação } \\
\text { coletiva }\end{array}$ & $\begin{array}{l}\text { Mediação } \\
\text { de conflitos } \\
\text { entre } \\
\text { nativos, } \\
\text { pescadores } \\
\text { e órgãos } \\
\text { públicos }\end{array}$ & $\begin{array}{l}\text { Desenvolvimento } \\
\text { de políticas } \\
\text { públicas que } \\
\text { priorizem o } \\
\text { turismo }\end{array}$ & $\begin{array}{l}\text { Comercialização } \\
\text { de PFNMs, } \\
\text { como principal } \\
\text { fonte de renda }\end{array}$ & $\begin{array}{l}\text { Implantação de } \\
\text { políticas de } \\
\text { desenvolvimento } \\
\text { no Parque } \\
\text { Nacional }\end{array}$ & $\begin{array}{l}\text { Novas formas } \\
\text { de } \\
\text { aproveitamento } \\
\text { do Baru e } \\
\text { dificuldades } \\
\text { com a redução } \\
\text { da produçąo }\end{array}$ & $\begin{array}{l}\text { Reorganização } \\
\text { produtiva com } \\
\text { o capim } \\
\text { dourado e do } \\
\text { turismo }\end{array}$ & $\begin{array}{l}\text { Criação da } \\
\text { Reserva } \\
\text { Extrativista do } \\
\text { Mandira e } \\
\text { manejo de } \\
\text { recursos } \\
\text { marinhos }\end{array}$ & $\begin{array}{l}\text { A captação e } \\
\text { aplicação de } \\
\text { recursos } \\
\text { aumentou a } \\
\text { produtividade }\end{array}$ & $\begin{array}{l}\text { Patenteamento } \\
\text { dos } \\
\text { conhecimentos } \\
\text { tradicionais } \\
\text { dos Wapichana }\end{array}$ & $\begin{array}{l}\text { Estratégias de } \\
\text { conservação e } \\
\text { utilização da } \\
\text { agrobiodiversidade }\end{array}$ \\
\hline 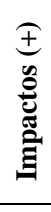 & $\begin{array}{l}\text { Aumento da } \\
\text { renda e } \\
\text { acesso à } \\
\text { tecnologia }\end{array}$ & $\begin{array}{l}\text { Divulgação } \\
\text { dos valores } \\
\text { históricos e } \\
\text { culturais da } \\
\text { região }\end{array}$ & $\begin{array}{l}\text { Ações favoráveis } \\
\text { a preservação } \\
\text { ambiental }\end{array}$ & $\begin{array}{l}\text { Novas fontes de } \\
\text { renda }\end{array}$ & $\begin{array}{l}\text { Potencialidades } \\
\text { naturais, } \\
\text { históricas e } \\
\text { culturais }\end{array}$ & $\begin{array}{l}\text { Aumento e } \\
\text { diversificação } \\
\text { das fontes de } \\
\text { renda }\end{array}$ & $\begin{array}{l}\text { Potencial de } \\
\text { organização e } \\
\text { resistência dos } \\
\text { moradores }\end{array}$ & $\begin{array}{l}\text { Atividade } \\
\text { sustentável e } \\
\text { aumento da } \\
\text { renda com a } \\
\text { criação da } \\
\text { cooperativa } \\
\end{array}$ & $\begin{array}{l}\text { Manejo de } \\
\text { juçara para } \\
\text { produção de } \\
\text { polpa }\end{array}$ & $\begin{array}{l}\text { Discussão } \\
\text { sobre a } \\
\text { preservação do } \\
\text { território }\end{array}$ & $\begin{array}{l}\text { Manutenção da } \\
\text { agrobiodiversidade }\end{array}$ \\
\hline 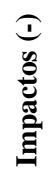 & $\begin{array}{l}\text { Mudanças no } \\
\text { uso do solo }\end{array}$ & $\begin{array}{l}\text { Desordem, } \\
\text { conflitos e } \\
\text { lutas de } \\
\text { classes }\end{array}$ & $\begin{array}{l}\text { Interesse privado } \\
\text { no turismo de } \\
\text { forma simplória e } \\
\text { desestruturada }\end{array}$ & $\begin{array}{l}\text { Efeitos } \\
\text { negativos nas } \\
\text { atividades de } \\
\text { subsistência }\end{array}$ & $\begin{array}{l}\text { Falta de } \\
\text { iniciativas para } \\
\text { desenvolver os } \\
\text { potenciais da } \\
\text { região }\end{array}$ & $\begin{array}{l}\text { Pouca } \\
\text { diversidade de } \\
\text { produtos } \\
\text { coletados }\end{array}$ & $\begin{array}{l}\text { Titulação do } \\
\text { território e } \\
\text { falta de } \\
\text { produção de } \\
\text { alimentos }\end{array}$ & $\begin{array}{l}\text { Redução dos } \\
\text { estoques naturais }\end{array}$ & $\begin{array}{l}\text { Corte de } \\
\text { palmito }\end{array}$ & $\begin{array}{l}\text { Apropriação } \\
\text { dos } \\
\text { conhecimentos } \\
\text { tradicionais }\end{array}$ & $\begin{array}{l}\text { Realizou apenas a } \\
\text { avaliação } \\
\text { econômica }\end{array}$ \\
\hline
\end{tabular}

FONTE: Org.: dos Autores (2019). 
Os trabalhos apresentados no Quadro 3 sugerem que a pr dos pesquisadores é estudar comunidades amazônicas. Um dos fatores determinantes para o interesse pela Amazônia é ser a maior reserva do mundo e o maior bioma do Brasil (IBGE, 2010). Além disso, a região possui muitas comunidades ribeirinhas e tradicionais que se dedicam ao fornecimento de produtos da biodiversidade para o mercado nacional e internacional (FARIA, 2007; VIEIRA et al., 2017).

A margem dos contratos de fornecimento, alguns ativos sofrem com a biopirataria por terem conhecimento tradicional associado como o cunani e o biribiri, outros movimentam o extrativismo como o capim dourado, baru, sementes de mogno, palmito juçara, ou ainda, são cultivados como as mandiocas açucaradas, maracujá-doce e as ostras. Em comum, os produtos representam a ligação das comunidades com a biodiversidade, sua forma de consumo e produção conjugam esforços para proteger o meio ambiente e aos mesmo tempo aumentar a renda das famílias.

Das pesquisas selecionas, apenas uma comunidade firmou um contrato para fornecer matéria-prima, ou seja, essa formalização não é tão frequente. Tradicionalmente as comunidades são agroextrativistas e comercializam seus produtos com grupos específicos ou no mercado regional. A falta de um mercado organizado faz com que as famílias se dediquem ao extrativismo como forma de melhorar a renda até surgir outra atividade com remuneração fixa. Para a maioria, no início o extrativismo parece ser um bom negócio, mas a falta de organização e estruturação de tarefas acaba tornando a atividade desinteressante por não aumentar os ganhos.

Em um dos casos, a população residente em Vila Mota-PA apresenta reduzida capacidade organizativa na produção e dificuldades para tomar decisões sobre objetivos de curto, médio e longo prazo. Muitas comunidades apresentam as mesmas dificuldades com práticas de gestão simples que priorizam a organização interna dos produtores e a solução de problemas operacionais (PINHEIRO; DARNET, 2014). Por outro lado, iniciativas como o projeto Biocomércio Andino na Colômbia, realizado na sede municipal de Leticia, apoiou 22 iniciativas em ecoturismo, sendo os principais o Parque Mundo Amazónico e Tanimboca. Após o projeto os empreendimentos conseguiram alcançar a viabilidade econômica, integração das comunidades pelos serviços oferecidos, conservação do meio ambiente, qualidade de vida para seus colaboradores, conservação dos recursos naturais e aumento sustentável das vendas (CAF, 2014).

O maior impacto para as comunidades que estão envolvidas em processos de comercialização de algum produto da biodiversidade é o aumento da renda familiar. A expectativa financeira motiva o início da atividade e proporciona uma melhoria na qualidade de vida aos produtores dando acesso à tecnologia e infraestrutura. Por outro lado, com mais recursos é comum que as pessoas deixem as comunidades com mais frequência e também reduzam a lavoura de 
subsistência para comprar os produtos no mercado local. Outras implicações estão relacionadas a preservação do meio ambiente, redução dos estoques naturais, conflitos dentro da comunidade e biopirataria. Como sugestão, Medina e Barbosa (2016) indicam a falta de estudos sobre as práticas operacionais de forma detalhada que podem servir de base para a inclusão das populações locais.

O ecoturismo é uma opção econômica para complementar a renda e promover a conservação do patrimônio natural e cultural. No caso do ecoturismo comunitário, é essencial fortalecer os empreendimentos existentes na perspectiva da cadeia de valor, com a participação de organizações ligadas às iniciativas. Além disso, o aumento no número de visitantes que chegam às áreas a cada ano é uma grande oportunidade para desenvolver o artesanato promovendo instrumentos financeiros para melhorar a capacidade produtiva dos grupos de artesãos.

Nesse sentido, são relevantes os estudos que não ignoram as práticas culturais, a relação com o tempo e o espaço geográfico e simbólico das comunidades tradicionais (SOUSA; PEZZUTI, 2017). Uma contribuição para o planejamento de pesquisas dessa natureza é apresentada na Figura 2, um quadro conceitual sobre o biocomércio em comunidades tradicionais que pode orientar pesquisas do ponto de vista dos parceiros associados a uma rede de suprimentos, que incluem fornecedores, clientes, logística e empresa focal.

\section{FIGURA 2. POSICIONAMENTO DA PESQUISA SOBRE BIOCOMÉRCIO EM COMUNIDADES TRADICIONAIS}
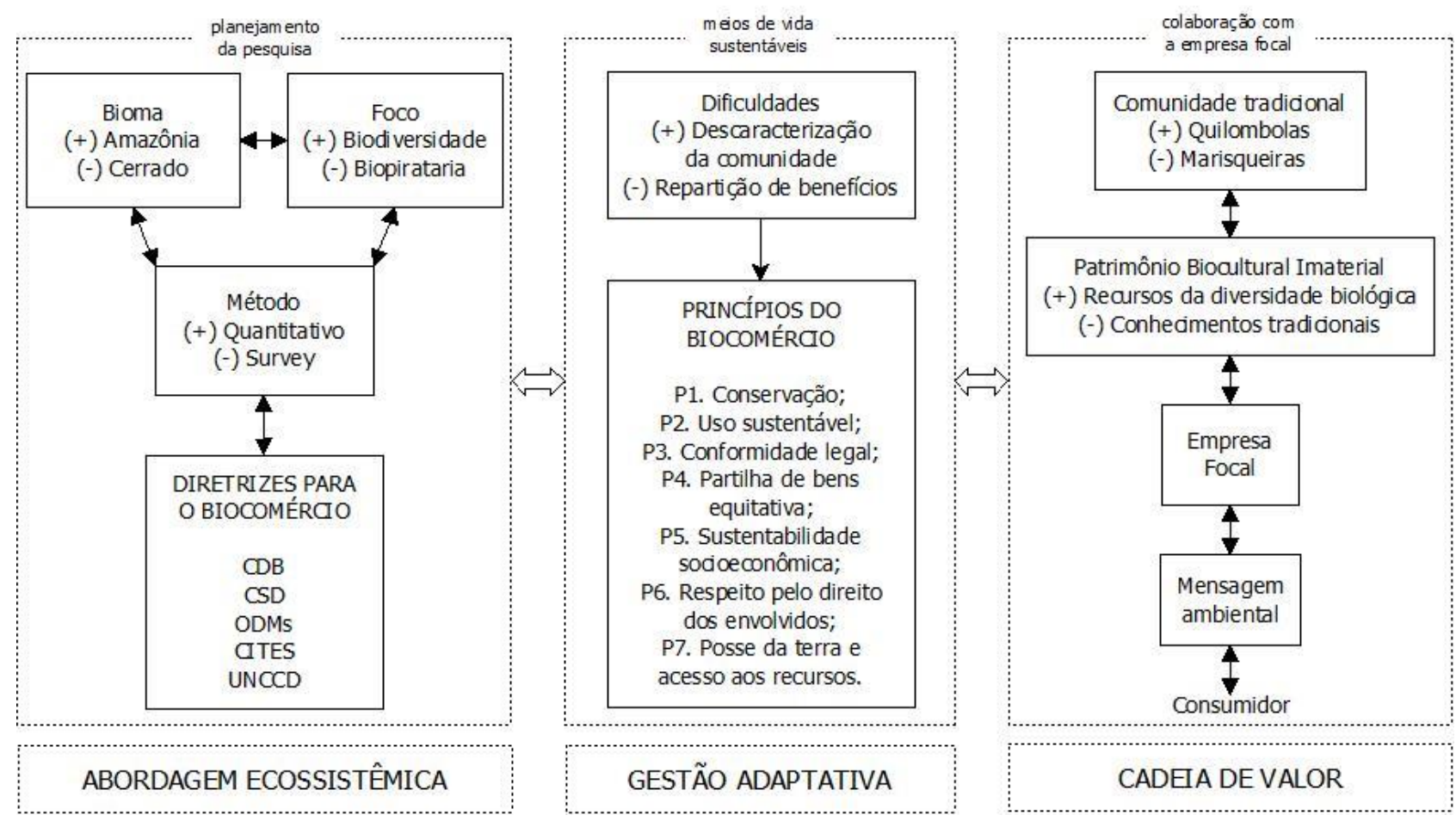

FONTE: Org.: dos Autores (2019). 
Para posicionar a pesquisa foram consideradas três abordagens teóricas interdependentes: abordagem ecossistêmica, gestão adaptativa e cadeia de valor. As teorias estão abaixo da estapa correspondente na pesquisa cumprindo o papel de orientar a análise e orientar nas pesquisas sobre o tema.

Abordagem ecossistêmica pretende garantir a sustentabilidade de funções ecológicas por muito tempo, permitindo que as futuras gerações possam usufruir das condições dos ecossistemas que estão disponíveis atualmente para população. De acordo com Mitchel (1997), essa metodologia defende posturas rigídas em relação às questões ambientais ao considerar que as instituições devem se adaptar a mudança e um processo decisório colaborativo. Para essa fase da pesquisa, a metodologia contribuiu com uma visão holística que integra questões ecológicas e sociais, bem como as interações envolvidas no sistema produtivo, afinal, na etapa de planejamento da pesquisa estavam reunidas as categorias mais abrangentes para definição do estudo.

A gestão adaptativa é uma abordagem gerencial preparadada para prover os sistemas organizacionais com maior grau de adaptabilidade, buscando meios para aumentar a velocidade de resposta às pressões ambientais melhorar a qualidade dessa resposta (MELO, 2007). Nesta fase, ao identificar as dificuldades enfrentadas pelas comunidades, os princípios do biocomércio, os meios de vida sustentáveis e as relações comerciais em busca de uma melhor condição financeira, propõese essa abordagem para que a comunidade siga a mesma lógica e assegure a coerência do empreendimento e, consequentemente, seu bom desempenho.

Por fim, para produzir com valor agregado os produtos devem se benificar de todas as funções da cadeia de valor, ter um bom projeto, marca, ser flexível e chegar ao consumidor por um preço acessível. Para as comunidades, o grande problema é a falta de competência para dominar todas as etapas da cadeia de valor, além das dificuldades para a gestão das etapas. Nesse contexto, a atuação de uma empresa focal a montante pode viabilizar o biocomércio beneficiando povos e comunidades tradicionais. A jusante a empresa entrega ao consumidor um produto com valor agregado e mensagem ambiental após ter adquirido e processado um dos produtos da biodiversidade.

O quadro conceitual incentiva pesquisas que ultrapassem a noção operacional e contribuam para o reconhecimento das comunidades tradicionais dotadas de saberes e competências para a produção de insumos de qualidade (SOUSA; PIRAUX, 2015). No caso das marisqueiras de Barra Grande-PI, o conhecimento popular sobre o marisco está em harmonia com a literatura especializada (FREITAS et al., 2012). Em outro exemplo, o avanço do desmatamento incentivou um projeto para o manejo das florestas focado na produção de Camu-camu (Myrciari Dubia), na 
Amazônia colombiana. Dentre outros êxitos, o projeto logrou: aumentar as capacidades de comércio em 12 espécies não-madeireiras na Colômbia (açaí, copaíba, andiroba, araçá, cupuaçu, pupunha, urucum, chambá, baunilha, etc.); fortalecer os processos de 23 associações de produtores; 437 hectares de influência direta sobre os princípios e critérios de biocomércio na categoria de Produtos Florestais Não-Madeireiros (PFNM) (CAF, 2014).

Há muitos problemas pendentes de solução no território brasileiro, como a luta pelos direitos sociais básicos e ao território, acesso aos recursos naturais e políticas públicas adequadas às necessidades. Novas pesquisas podem colaborar com a viabilidade do biocomércio tratando as dificuldades enfrentadas nas parcerias, definindo e mensurando os objetivos e resultados, aplicando uma perspectiva comparativa entre as comunidades tradicionais, discutindo a produção sustentável, diversidade de produtos, agregação de valor, comercialização, uso de tecnologias, associativismo e cooperativismo. Para tanto, observar o passado em termos de estudos pode ser útil para planejar as pesquisas futuras e atuar em áreas pouco favorecidas dentre todas as dificuldades enfrentadas pelas comunidades tradicionais.

\section{Considerações finais}

Esse artigo teve como objetivo empreender um mapeamento das pesquisas atuais sobre acordos entre comunidades tradicionais e empresas para o fornecimento de produtos da biodiversidade. Ao longo de quatro fases foram analisadas 73 pesquisas sobre o tema comunidades tradicionais. Durante o desenvolvimento das etapas, foi dada ênfase a trabalhos que tiveram como foco o comércio de produtos da biodiversidade e a partir do conceito de biocomércio cunhado pela UNCTAD (2006), as pesquisas foram classificadas e mapeadas para identificar eventuais lacunas na literatura e posicionar adequadamente novas inciativas de investigação.

Os resultados indicam algumas tendências como a preferência por comunidades tradicionais localizadas na Amazônia, falta de pesquisas com o foco em bioprospecção, ausência de métodos de pesquisas combinados, concentração dos trabalhos em poucas categorias de comunidades tradicionais e muitas dificuldades que as comunidades enfrentam. Esta fase da pesquisa oferece um panorama geral e preocupante ao considerar que as pesquisas estão concentradas em algumas categorias de classificação enquanto outras foram pouco investigadas.

$\mathrm{O}$ artigo tem muitas contribuições. Primeiro mantém uma abordagem objetiva e imparcial na coleta de dados. Assim, uma diferença significativa é observada nos resultados a partir do estudo de 
teses e dissertações que abordaram problemas regionais e não estão publicadas em periódicos. $\mathrm{Na}$ análise de categorias, bioma, foco, método, PBI, comunidade tradicional e dificuldades apresentam um resultado bastante diferente dos encontrados na literatura. Além disso, os 11 trabalhos que estudaram uma relação comercial entre comunidade e empresa privada oferecem ao leitor novas possibilidades de olhar para o biocomércio. Por fim, o trabalho apresenta uma estrutura conceitual abrangente que integra as categorias pesquisadas e os princípios e abordagens do biocomércio.

As pesquisas que apresentaram acordos ou parcerias com empresas privadas tem dificuldade para desenvolver todos os princípios do biocomércio, ficando evidente o foco no produto ou serviço e seu maior resultado o aumento da renda e emprego para as famílias. A biodiversidade é explorada em diversas frentes de trabalho, porém, as iniciativas encontram dificuldades para promover o desenvolvimento das organizações, a distribuição equitativa dos resultados e a manutenção do modo de vida tradicional. Ainda são comuns casos de biopirataria e exploração da mão-de-obra com valores abaixo do normal para a atividade.

Verificam-se várias mudanças sociais nas comunidades ocasionadas pelo aumento da renda, apesar de melhorar a condição de vida das famílias, as parcerias continuam suplementares na geração de renda e não centrais. Como consequência, há dependência de agentes econômicos externos e sensibilidade a sazonalidade do mercado. Na prática, as comunidades perdem valores tradicionais, sofrem diferenciação social, desigualdade econômica e mudança dos hábitos alimentares dos grupos envolvidos. O impacto ambiental decorrente de acordos entre grupos locais e empresas ocorre de forma direta, pelo aumento na extração do recurso explorado para comercialização ou indireta, pela inserção de novas tecnologias e exploração dos demais recursos.

Como pesquisa futura, sugere-se investigações que ultrapassem a fase operacional dos acordos e contribuam para o reconhecimento da relação de biocomércio enquanto atividade de coleta, produção, transformação e comercialização de bens e serviços derivados da biodiversidade, que se aplicam os critérios de sustentabilidade. Recomenda-se considerar as formas de vida e os saberes, historicamente construídos, demonstrando compasso entre os objetivos públicos e os povos que dão vida a região.

\section{Referências}

ATTUCH, I. M. Conhecimentos tradicionais do Cerrado: sobre a memória de Dona Flor, raizeira e parteira. 2006. 147 f. Dissertação (Mestrado em Antropologia) - Universidade de Brasília, Brasília, 2006. 
BANCO DE DESARROLLO DE AMÉRICA LATINA (CAF). Biocomercio Andino: Quince historias de éxito em Colombia, Ecuador y Peú. Trivia Comunicación Creativa: Perú, 2014.

BRASIL. Decreto n. 6.040, de 7 de fevereiro de 2007. Institui a Política Nacional de Desenvolvimento Sustentável dos Povos e Comunidades Tradicionais. Brasília, DF, 2007.

BERKES, F., COLDING, J., FOLKE C. Rediscovery of traditional ecological knowledge as adaptive management. Ecological Applications, Washington, v. 10, n. 5, p. 1251-1262, 2000.

CALEGARE, M. G. A.; HIGUCHI, M. I. G.; BRUNO, A. C. S. À visibilidade política de grupos sociais portadores de identidade étnica e coletiva. Ambiente \& Sociedade, São Paulo, v. 17, n. 3, p. 115-134, 2014.

CAVALCANTI, C. M. Impactos socioambientais locais decorrentes de acesso aos recursos genéticos para fins comerciais. 2010. 216 f. Dissertação (Mestrado em Ecologia de Agroecossistemas) - Ecologia de Agroecossistemas, Universidade de São Paulo, Piracicaba, 2010.

CHAVES, M. R.; BARROSO, S. C.; LIRA, T. M. Populações tradicionais: manejo dos recursos naturais na Amazônia. Revista Praia Vermelha, Rio de Janeiro, v. 19, n. 2, p. 111-122, 2009.

DIEGUES, A. C. S. O mito moderno da natureza intocada. 3. ed. São Paulo: Hucitec/Núcleo de Apoio à Pesquisa sobre Populações Humanas e Áreas Úmidas Brasileiras/USP, 2000.

ENRÍQUEZ, G. Desafios da sustentabilidade da Amazônia: biodiversidade, cadeias produtivas e comunidades extrativistas integradas. 2008. 460 f. Tese (Doutorado em Desenvolvimento Sustentável) - Universidade de Brasília, Brasília, 2008.

ENRÍQUEZ, G. Amazônia: Rede de inovação de dermocosméticos Sub-rede de dermocosméticos na Amazônia a partir do uso sustentável de sua biodiversidade com enfoques para as cadeias produtivas da castanha-do-pará e dos óleos de andiroba e copaíba. Revista Parcerias Estratégicas, Brasília, v. 14, n. 28, p. 51-118, 2009.

FABIANO, C. C. L. O turismo e a sua contribuição na manutenção e na preservação da pesca artesanal e da cultura tradicional na reserva extrativista marinha de Arraial do Cabo - RJ. 2011. 152 f. Dissertação (Mestrado Profissional em Turismo) - Universidade de Brasília, Brasília, 2011.

FALCÃO, L. B. Turismo em Resex: perspectivas de desenvolvimento, participação social e políticas públicas nas RESEX de Soure e de Curuçá no Pará. 2013. 131 f. Dissertação (Mestrado Profissional em Turismo) - Universidade de Brasília, Brasília, 2013.

FARIA, R. B. M. Povos indígenas na Amazônia e o mercado de produtos florestais não madeireiros: efeitos no uso de recursos naturais pelos Araweté. 2007. 261 f. Dissertação (Mestrado em Ciência Ambiental) - Universidade de São Paulo, São Paulo, 2007.

FREITAS, S. T., PAMPLIN, P. A. Z.; LEGAT, J.; FOGAÇA, F. H. S.; BARROS, R. F. M. Conhecimento tradicional das marisqueiras de Barra Grande, área de proteção ambiental do delta do Rio Parnaíba, Piauí, Brasil. Ambiente \& Sociedade, São Paulo, v. 15, n. 2, p. 91-112, 2012. 
HUISINGH, D. Call for comprehensive/integrative review articles. Journal of Cleaner Production, s/n, p. 1-2, 2012.

INSTITUTO BRASILEIRO DE GEOGRAFIA E ESTATÍSTICA (IBGE). Mapa de biomas do Brasil. São Paulo: IBGE, 2010. Disponível em: http://ftp.ibge.gov.br/Cartas_e_Mapas/Mapas_Murais/. Acesso em 21 dez. 2017.

INTERNATIONAL SOCIETY OF ETHNOBIOLOGY (ISE). Código de Ética da ISE (com adições em 2008). 2006. Disponível em: http://www.ethnobiology.net/ethics.php. Acesso em: 08 jan. 2018.

JABBOUR, C. J. C. Environmental training in organisations: From a literature review to a framework for future research. Resources, Conservation and Recycling, Amsterdam, v. 74, p. 144-155, 2013.

KANTEK, R. T.; SAUTTER, K. D.; MICHALISZYN, M. S. Impactos ambientais na Área de Proteção Ambiental (APA) de Guaratuba, Paraná, Brasil, sob o ponto de vista de moradores tradicionais. Revista Sociedade \& Natureza, Uberlândia, v. 21, n. 2, p. 39-56, 2009.

KITCHENHAM, B.; BRERETON, P. A systematic review of systematic review process research in software engineering. Information and Software Technology, Amsterdam, v. 55, p. 2049-2075, 2013.

LIMA, M. A. L.; KAPLAN, D. A.; DORIA, C. R. C. Hydrological controls of fisheries production in a major Amazonian tributary. Ecohydrology, New Jersey, v. 19, p.1899-11, 2017.

LIRA, T. M.; CHAVES, M. P. S. R. Comunidades ribeirinhas na Amazônia: organização sociocultural e política. Interações, Belo Horizonte, v. 17, n. 1, p. 66-76, 2016.

LOBATO, G. J. M.; MARTINS, A. C. C. T.; LUCAS, F. C. A.; MORALES, G. P.; ROCHA, T. T. Reserva Extrativista Marinha de Soure, Pará, Brasil: modo de vida das comunidades e ameaças ambientais. Biota Amazônia, Macapá, v. 4, n. 4, p. 66-74, 2014.

MEDINA, G. S.; BARBOSA, C. W. S. A questão produtiva nas Reservas Extrativistas. Novos Cadernos NAEA, Guamá, v. 19, n. 2, p. 69-88, 2016.

MELO, M. A. C.; AGOSTINHO, M. C. E. Gestão Adaptativa: uma proposta para o gerenciamento de redes de inovação. Revista administração contemporânea, Curitiva, v. 11, n. 2, p. 93-111, 2007.

MELO, S. W. C. Extrativismo vegetal como estratégia de desenvolvimento rural no Cerrado. 2013. 197 f. Dissertação (Mestrado em Agronegócio) - Universidade de Brasília, Brasília, 2013.

MORSELLO, C. Company-community non-timber forest product deals in the Brazilian Amazon: a review of opportunities and problems. Forest Policy and Economics, Amsterdam, v. 8, p. 485-94, 2006. 
MITCHELL, B. (Org.). Resource and environmental management in Canada: addressing conflict and uncertainty. 2. ed. Toronto: Oxford University Press, 1997.

MWILUA, O. S.; COMYN-WATTIAUA, I.; PRAT, N. Design science research contribution to business intelligence in the cloud: A systematic literature review. Future Generation Computer Systems, Amsterdam, v. 63, p. 108-122, 2016.

PAWAR, M. Resurrection of traditional communities in postmodern societies. Futures, Amsterdam, n. 35, p. 253-265, 2003.

PINHEIRO, J. O. C.; DARNET, L. A. F. Comunidades tradicionais em áreas litorâneas da Amazônia: estudo sobre desenvolvimento local em Vila Mota, Pará, Brasil. Boletim do Museu Paraense Emílio Goeldi, Belém, v. 9, n. 1, p. 145-162, 2014.

PEREIRA, A. L. Famílias quilombolas: história, resistência e luta contra a vulnerabilidade social, insegurança alimentar e nutricional na Comunidade Mumbuca - Estado do Tocantins. 2012. $309 \mathrm{f}$. Tese (Doutorado) - Faculdade de Ciências e Letras de Araraquara, Araraquara, 2012.

PORRO, R.; PORRO, N. M. Social identity, local knowledge and adaptive management by traditional communities of the babassu region in Maranhão. Ambiente e sociedade, São Paulo, v. 18, n. 1, p. 1-18, 2015.

ROWE, F. What literature rewiew is not: diversity, boundaries and recommendations. European Journal of Information Systems, New York, v. 23, p. 241-255, 2014.

SILVA, R. J. N. Políticas Públicas agroecológicas para comunidades quilombolas: um estudo de caso a partir do território. 2014. 148 f. Tese (Doutorado em Ecologia Aplicada) - Ecologia de Agroecossistemas, Piracicaba, 2014.

SOUSA, F. F.; PIRAUX, M. A construção social da qualidade da farinha de mandioca em comunidades rurais na Amazônia paraense. Novos Cadernos NAEA, Guamá, v. 18, n. 3, p. 199$222,2015$.

SOUSA, G. S.; PEZZUTI, J. C. B. Breve ensaio sobre a lógica subjetiva dos povos e comunidades tradicionais amazônicas. Novos Cadernos NAEA, Guamá, v. 20, n. 2, p. 111-126, 2017.

SOUZA, S. E. X. F. de. Manejo de Euterpe edulis Mart. para produção de polpa de fruta: subsídios à conservação da biodiversidade e fortalecimento comunitário. 2014. Tese (Doutorado em Recursos Florestais) - Universidade de São Paulo, Piracicaba, 2014.

TANGA, R.; GAVINC, M. C. A Classification of Threats to Traditional Ecological Knowledge and Conservation Responses. Conservation and Society, Bengaluru, v. 14, n. 1, p. 57-70, 2016.

TRINDADE, D. P. A Proteção dos conhecimentos tradicionais associados das comunidades indígenas: o cunânio e o biribiri, povo Wapichana. 2011. Tese (Doutorado em Direito Ambiental) Universidade do Estado do Amazonas, Amazonas, 2011.

UNITED NATIONS CONFERENCE ON TRADE AND DEVELOPMENT (UNCTAD). Principios y Criterios de Biocomercio. Iniciativa BioTrade. Ginebra, 2006. 
UNG, C. O. L.; HARNETT, J.; HU, H. Community pharmacist's responsibilities with regards to Traditional Medicine/Complementary Medicine products: A systemic literature review. Research Social and Administrative Pharmacy, New York, v. 13, n. 4, p. 686-716, 2017.

Artigo recebido em 04/04/2019. Aceito para publicação em 02/07/2019. 